Tropical Journal of Pharmaceutical Research April 2016; 15 (4): 847-854

ISSN: $1596-5996$ (print); 1596-9827 (electronic)

(C) Pharmacotherapy Group, Faculty of Pharmacy, University of Benin, Benin City, 300001 Nigeria.

All rights reserved.

Available online at http://www.tjpr.org

Original Research Article

http://dx.doi.org/10.4314/tjpr.v15i4.26

\title{
Community pharmacists' understanding, attitudes, practice and perceived barriers related to providing pharmaceutical care: a questionnaire-based survey in Macao
}

\author{
Carolina Oi Lam Ung, Chon Kit Chao, Yuanjia Hu, Jing Zhao, Peng Li, Yitao \\ Wang and Hao Hu* \\ State Key Laboratory of Quality Research in Chinese Medicine, Institute of Chinese Medical Sciences, University of Macau, \\ Macao
}

*For correspondence: Email: haohu@umac.mo; Tel: 00853-88228538; Fax: 00853-28841358

\begin{abstract}
Purpose: To explore the knowledge, attitudes, practice and perceived barriers of community pharmacists regarding provision of pharmaceutical care as well as provide recommendations on how to advance the service during the early stage of development in Macao.

Methods: A questionnaire comprising 10 items was used to collect respondents' demographic information and to evaluate their understanding of pharmaceutical care, attitude towards service provision, current practice and perceived barriers. Descriptive and comparative analysis of the results was conducted.

Results: While $95 \%$ of the participating pharmacists agreed that patients' health was their primary responsibility, only $57 \%$ believed that they can provide better pharmaceutical care in the future. The majority spent most of their work time counselling patients (90\%) and checking prescription (70\%). Only a small portion monitored adverse drug reaction and drug compliance (44\%), engaged in health screening or drug safety promotion (20\%) or maintained patient medication records (4\%). Insufficient communication with physicians (90\%), lack of time (79 \%) and lack of physical space at the pharmacy (76\%) were considered the most significant barriers.

Conclusion: A suboptimal level of pharmaceutical care is provided by pharmacists in Macao. Considering the barriers identified and integrating other country experiences, establishing an enabling atmosphere using policy and regulatory measures is the fundamental element for advancing pharmaceutical care by community pharmacists.
\end{abstract}

Keywords: Community pharmacist, Community Pharmacy, Pharmaceutical care, Macao

\begin{abstract}
Tropical Journal of Pharmaceutical Research is indexed by Science Citation Index (SciSearch), Scopus, International Pharmaceutical Abstract, Chemical Abstracts, Embase, Index Copernicus, EBSCO, African Index Medicus, JournalSeek, Journal Citation Reports/Science Edition, Directory of Open Access Journals (DOAJ), African Journal Online, Bioline International, Open-J-Gate and Pharmacy Abstracts
\end{abstract}

\section{INTRODUCTION}

Rational use of medicines can help increase longevity and quality of life for individuals. However, medication use without due care especially among the chronically-ill, aging population is associated with suboptimal clinical outcomes and increased risks of drug-related problems (DRPs), resulting in preventable personal suffering and costly health expenditures. Pharmaceutical care provided by pharmacists is considered as one of the key practice to alleviate the risks of DRPs [1,2]. In 1990, Hepler and Strand formulated the concept of pharmaceutical care, defining it as "the responsible provision of drug therapy for the purpose of achieving definite outcomes which improve a patient's quality of life" [3]. This vision 
was shared by many countries and professional groups around the world as a milestone for professional development. More and more pharmacists have become increasingly patientfocused and proactive in acting responsibly to optimize clinical outcome of pharmacotherapy and to minimize associated risks. In the US, European countries, Canada and New Zealand, pharmaceutical care has been well integrated into most pharmacists' routine practice [4-6]. Benefits of pharmaceutical care have been fully demonstrated in terms of clinical outcome and many other aspects such as patients' compliance, health literary and disease screening [7-14].

Depending on the legal, political and health care systems, different forms and levels of pharmaceutical care development and adoption have been observed across countries [8]. In pursuit of continuous advancement, research efforts have been made to identify possible barriers hindering the development of this professional service. Similar set of barriers have been found in many countries, the significance of each barrier varied greatly, which warrants approach and policy specific to the national situation. For instance in the US, lack of reimbursement system was considered the most important barrier $[15,16]$ whereas in Iran and Pakistan, ambiguity about the professional role of pharmacists and the concept of pharmaceutical care were found to limit the development of pharmaceutical care service $[17,18]$.

Despite increasing concerns over DRPs, the extent of pharmaceutical care provision and possible barriers in Macao has never been examined before. The objectives of this study were to examine the pharmacists' level of understanding of pharmaceutical care, their attitude towards and current practice of the service, and the perceived barriers. It is anticipated that the study will put forward recommendations on how to advance the service in areas where pharmaceutical care is only at the early stage of development.

\section{EXPERIMENTAL}

\section{Study design}

The conceptual framework used to design this questionnaire was based on the pharmaceutical care model found in the literature [3]. A similar study [19] was also consulted and special elements unique to the business environment of community pharmacies in Macao considered when designing the semi-structured questionnaire.

\section{Setting}

Macao has a population of 600,000 and was used as the study target. It is a small city where East meets West in almost every aspect including pharmacy practice. Pharmacy practice in the city has undergone dramatic changes since its reversion to China in 1999. The number of community pharmacies increased from 46 in 2003 to 193 in 2013 and the number of registered pharmacists increased from 89 to 381 during the same period of time. The legal responsibilities of registered pharmacists still confined to dispensing, medicine storing and providing, and quality and bio-chemical analysis of drug products. However, concerns over DRPs are increasing due to aging population, over-use of medications, poly-doctor, self-medications, and concurrent use of conventional medicine and traditional medicines.

\section{Data collection}

The study was conducted in community pharmacies in Macao from January to February 2014. Personal visit by researchers at randomlyselected community pharmacies was used to distribute and retrieve self-administered questionnaires completed by community pharmacists.

\section{Study instrument}

The questionnaire was developed originally in English. Considering that Chinese would be the first language of most respondents, the questionnaire was translated into Chinese by the authors. The English content was kept for respondents' reference to original expressions of the questions. A pre-test of the questionnaire was carried out with the participation of 5 community pharmacists to assess the appropriateness of wordings and format of the questionnaire. Minor modifications were made based on their comments to achieve the final version of the questionnaire.

The questionnaire consisted of five sections. The first section collected demographic data of the respondents such as gender, age, type of pharmacy they were practising, number of years of working experiences in pharmacy, highest pharmacy-related qualification, and prescription volume. In the second section, pharmacists were questioned about six statements regarding the concept, purpose and procedures of pharmaceutical care, and the role of pharmacists 
on this matter. A 5-point Likert scale was adopted as the statement rating system ranging from $1-$ not at all to $5=$ very much. The third section consisted of 7 questions about pharmacists 'attitudes to pharmaceutical care. The fourth section asked about the frequency of the nine pharmaceutical care activities pharmacists performed during their daily practice using the scale $1=$ never through $5=$ always. These activities included DRP identification, DRP solving, follow-up evaluation, documentation in practice, health education, etc. In the last section, there were 11 questions regarding the barriers to the provision of pharmaceutical care in Macao. These barriers included lack of time, inadequate communication with doctors, lack of supportive policies, etc. In the third and last section, the 5-point Likert scale was used again by the pharmacists to express the level of agreement to the statements regarding their perceptions and barriers, where $1=$ strongly disagree to 5 = strongly agree.

\section{Data analysis}

SPSS 20.0 was used for data analysis. In the first section, the demographic data of the respondents were analysed using descriptive statistics. For the core of this study, which is sections 2 to 5 , in addition to descriptive statistics, means was also used to determine the overall response of the respondents. Reliability of the scale used was tested using Cronbach's alpha (minimum 0.5, ideally between 0.7 - 0.8). In addition, ANOVA was used to perform integrative analysis of the demographic data of the respondents collected in section 1 and the data collected in the core part of study to infer any association between the background of the pharmacists and their perceptions about pharmaceutical care.

\section{Ethical approval}

The research was reviewed and approved by the Ethic Committee of University of Macau.

\section{RESULTS}

\section{Demographics}

Of the total of 107 questionnaires sent out in the survey, 102 responses were received giving a response rate of $95.3 \%$. Among the received responses, two of them were not completed and were thus excluded. 100 responses were included in data analysis, giving a final response rate of $93.5 \%$. Demographic data of the respondents are listed in Table 1. The majority of the respondents were female $(61 \%)$, aged between 21 - 30 years (84\%), worked in chain pharmacies (more than 4 stores owned by the same organization) (73\%), had only worked for $<5$ years compared to > 10 years $(9 \%)$, and held a bachelor degree as the highest pharmacyrelated qualification. In other words, most of the community pharmacists in Macao were new female graduates and work in chain pharmacies with limited practice experiences.

The proportions of workload related to prescription medicines were found to be "less than $10 \%$ " for $42 \%$ of respondents, "11 - $20 \%$ " for $14 \%$ of respondents, "21 - $40 \%$ " for $13 \%$ of respondents, " 41 - $50 \%$ " for $9 \%$ of respondents and " more than $50 \%$ " for $22 \%$ of respondents. This data indicated a two-end distribution of job responsibility of prescription medicines. The low workload proportion in handling prescription medicines partly reflected the fact that many pharmacies in Macao served tourists mainly, which applied to the majority of the respondents 'workplace. For the pharmacists who were able to dedicate $50 \%$ workload to prescription medicines, the pharmacies were considered as prescription medicines oriented which usually participated in the government medicinesubsidizing scheme. This represented $22 \%$ of the respondents' workplace. All the other pharmacies where the respondents worked were considered as neighbouring pharmacies.

\section{Pharmacists' understanding of pharmaceutical care}

Table 2 shows the respondents' understanding of the concept of pharmaceutical care. Although respondents' understanding of the purpose of use of pharmaceutical care was satisfactory as shown in their responses to statements 2 and 4, their comprehension of the key attitude which is the responsible provision of pharmaceutical care was only acceptable with only $70 \%$ respondent agreeing to Statement 1 . The confusion about their roles in pharmaceutical care was further indicated as only $58 \%$ respondents believed that all patients taking medicines require pharmacists' help. Statements 3 and 6 were the two false items to test the respondents 'replies. Table 2 also shows that the respondents had higher agreement on Statement 2 (Mean = 4.39), and Statement 4 (Mean = 4.09). Cronbach's alpha over the 6 statements was 0.509 . 
Table 1: Demographic profile of the respondents $(N=100)$

\begin{tabular}{lll}
\hline Variable & & $\%$ \\
\hline Sex & Male & 39 \\
Age & Female & 61 \\
& $21-30$ & 84 \\
& $31-40$ & 13 \\
Type of Pharmacy & $41-50$ & 2 \\
& $>50$ & 1 \\
Number of years in & Chain pharmacy & 70 \\
pharmacy practice & Independent pharmacy & 30 \\
& $\leq 5$ & 73 \\
Highest pharmacy-related & $6-10$ & 18 \\
qualification & $11-20$ & 8 \\
Proportion of workload & Bachelor & 1 \\
related to prescription & Master & 94 \\
medicines & $110 \%$ & 6 \\
& $11 \%-20 \%$ & 42 \\
& $21 \%-40 \%$ & 14 \\
& $41 \%-50 \%$ & 13 \\
& $>50 \%$ & 9 \\
& & 22
\end{tabular}

Table 2: Pharmacists' understanding of pharmaceutical care $(N=100)$

\begin{tabular}{lcc}
\hline Statement & $\begin{array}{c}\text { Agree and strongly } \\
\text { agree (\%) }\end{array}$ & $\begin{array}{c}\text { Mean } \\
\text { score }\end{array}$ \\
\hline 1. Pharmaceutical care is the responsible provision of drug & $70 \%$ & 3.74 \\
therapy & $97 \%$ & 4.39 \\
2. The aim of pharmaceutical are is to ensure the safety, & & 2.34 \\
efficacy, economy and rational use of medicines & $12 \%$ & 4.09 \\
3. Pharmaceutical care is just a medication counselling service & $90 \%$ & 3.56 \\
4. Pharmaceutical care provides a feedback to optimize drug & $58 \%$ & 2.27 \\
$\quad$ use & $13 \%$ & \\
5. All patients taking medicines require pharmacists 'help & & \\
6. The pharmacist plays secondary role in the pharmaceutical \\
care process
\end{tabular}

\section{Pharmacists' attitudes to pharmaceutical care}

Table 3 illustrates the results of respondents 'attitudes to pharmaceutical care. The respondents generally had a positive attitude and good determination to the provision of pharmaceutical care, $95 \%$ of them agreed that patients' health was their primary responsibility and would try their best to provide patients with the most suitable medicine as shown in their responses to statements 1 and 2 . The results of statements 5 and 7 also indicated that $89 \%$ of them were willing to provide the service and 98 $\%$ acknowledged the expectations of the patients. $79 \%$ of them were already conscious about the economy factor when choosing suitable medicines for their patients and $87 \%$ considered the provision of quality pharmaceutical care a source of job satisfaction as shown by the responses to statements 3 and 6. However, only $57 \%$ of the respondents believed that they could provide more comprehensive pharmaceutical care in the future. Table 3 also shows that the respondents had the highest agreement on Statement 2 (Mean $=4.42$ ). Comparatively, they showed the lowest agreement on Statement 4 (Mean = 3.74). Cronbach's alpha over the 7 statements was 0.763.

\section{Perceived frequency of pharmaceutical care provision}

Table 4 lists the results of respondents 'perceived frequency of pharmaceutical care provision in their daily practice. $85-90 \%$ of the respondents spent considerable amount of time counselling with patients, instructing them about drug administration, dosage, and precautions, and providing general health information and medication information. Around $70 \%$ of the respondents reported that they spent some of the time or most of their time performing prescription checks and conducting health education. Only 44 $\%$ of the respondents monitored adverse drug reaction and drug compliance among patients as part of their usual practice. Less than $20 \%$ of the respondents engaged in health screening 
activities or drug safety promotion outside community pharmacy setting. Only $4 \%$ of the respondents created personal medication record. As shown in Table 4, the respondents had the highest agreement on Statement 1 (Mean = 4.16) and Statement 3 (Mean = 4.16). Comparatively, they expressed the much lower agreement on Statement 6 (Mean = 1.41), Statement 5 (Mean = 1.94), and Statement 9 (Mean = 1.99). Cronbach's alpha over the 9 statements was 0.744 .

\section{Perceived barriers to the provision of pharmaceutical care}

Table 5 lists the respondents' opinions on the possible factors that might have inhibited the provision of pharmaceutical care. Over $90 \%$ of the respondents agreed or strongly agreed that insufficient communication with physician was a barrier. $79 \%$ of the respondents expressed that lack of physical space for pharmaceutical care provision was the second factor. Lack of time to provide pharmaceutical care (76 \%), lack of patient acceptance of pharmaceutical care (71 $\%$, lack of compensation for pharmaceutical care provision (68\%), slow introduction of pharmacist law (66\%), and lack of face-to-face communication with patient (55\%) were also considered important factors by the respondents. However, less than $40 \%$ of the respondents thought that lack of support to pharmaceutical care from pharmacy owners (37\%), lack of effective communication skills (36\%), lack of support to pharmaceutical care from other health care professionals (33\%) and lack of knowledge about drug use $(29 \%)$ were highly relevant barriers. Table 5 also shows that the respondents had the highest agreement on Statement 9 (Mean $=4.31$ ) but the lowest agreement on Statement 7 (Mean $=2.72$ ).

In the ANOVA analysis, no significant findings indicating that there is no association between the background of the pharmacists and their perceptions about pharmaceutical care were observed.

Table 3: Pharmacists' attitudes to pharmaceutical care $(N=100)$

\begin{tabular}{lcc}
\hline Statement & $\begin{array}{c}\text { Agree and strongly agree } \\
\text { (\%) }\end{array}$ & $\begin{array}{c}\text { Mean } \\
\text { score }\end{array}$ \\
\hline 1. I think that maintaining patients 'health is my primary & 95 & 4.29 \\
responsibility & 95 & 4.42 \\
2. I try my best to provide patients with suitable medicines. & 79 & 3.95 \\
3. I consider patients 'economic situation in the process of & 57 & 3.74 \\
pharmaceutical care provision. & 89 & 4.00 \\
4. I can provide more comprehensive pharmaceutical care than & & 4.27 \\
what is provided now & 87 & 4.22 \\
5. I would like to provide pharmaceutical care but lack basic & 87 & \\
$\quad$ working conditions & & \\
7. Providing pharmaceutical care offers me job satisfaction & & \\
$\quad$ care & &
\end{tabular}

Table 4: Perceived frequency of pharmaceutical care provision $(N=100)$

\begin{tabular}{lcc}
\hline Statement & $\begin{array}{c}\text { Some of the } \\
\text { time and most } \\
\text { of the time (\%) }\end{array}$ & $\begin{array}{c}\text { Mean } \\
\text { score }\end{array}$ \\
\hline $\begin{array}{l}\text { 1. Communicate with patients or customers in the counselling } \\
\text { area }\end{array}$ & $90 \%$ & 4.16 \\
$\begin{array}{l}\text { 2. Perform prescription check } \\
\text { 3. Provide patients with direction for drug administration, } \\
\quad \text { dosage, and precautions }\end{array}$ & $73 \%$ & 3.94 \\
$\begin{array}{l}\text { 4. Monitor adverse drug reaction and drug compliance among } \\
\text { patients }\end{array}$ & $89 \%$ & 3.03 \\
$\begin{array}{l}\text { 5. Engage in health screening activities, such as blood pressure } \\
\text { measurement }\end{array}$ & $17 \%$ & 1.94 \\
$\begin{array}{l}\text { 6. Create personal medication record e.g. electronic health } \\
\text { record }\end{array}$ & $4 \%$ & 1.41 \\
$\begin{array}{l}\text { 7. Conduct health education for patients } \\
\text { 8. Provide general health information and medication information } \\
\text { to patients }\end{array}$ & $70 \%$ & 3.53 \\
$\begin{array}{l}\text { 9. Promote drug safety knowledge outside community pharmacy } \\
\text { settings }\end{array}$ & $19 \%$ & 4.08 \\
\hline
\end{tabular}


Table 5: Perceived barriers to the provision of pharmaceutical care $(N=100)$

\begin{tabular}{llc}
\hline Statement & $\begin{array}{c}\text { Agree and strongly } \\
\text { agree (\%) }\end{array}$ & $\begin{array}{c}\text { Mean } \\
\text { score }\end{array}$ \\
\hline 1. Lack of physical space for pharmaceutical care provision & $79 \%$ & 3.85 \\
2. The slow introduction of pharmacists' law & $66 \%$ & 3.89 \\
3. Lack of patient acceptance of pharmaceutical care & $71 \%$ & 3.88 \\
4. Lack of time to provide pharmaceutical care & $76 \%$ & 3.88 \\
5. Lack of face-to-face communication with patient & $55 \%$ & 3.42 \\
6. Lack of effective communication skills & $36 \%$ & 2.97 \\
7. Lack of knowledge about drug use & $29 \%$ & 2.72 \\
8. Lack of compensation for pharmaceutical care provision & $68 \%$ & 3.87 \\
9. Insufficient communication with physician & $92 \%$ & 4.31 \\
10. Lack of support to pharmaceutical care from pharmacy & $37 \%$ & 3.40 \\
$\quad$ Owners & & 3.38 \\
11. Lack of support to pharmaceutical care from other health & $33 \%$ & \\
$\quad$ care professionals & & \\
\hline
\end{tabular}

\section{DISCUSSION}

A typical pharmacist in Macao would most likely be a young female, who held a bachelor degree in Pharmacy and practised for only a few years, spending more than half of her working hours on duties unrelated to prescription medicines. The high response rate to the questionnaire (95.3\%) indicated a common interest in pharmaceutical care and younger pharmacists might imply a higher level of acceptance and understanding of the professional service [4]. Many of them also showed a satisfactory understanding of the overall concept of pharmaceutical care. Nevertheless, a low level of pharmaceutical care was also observed. Less than $75 \%$ fully recognized the need to act proactively which might profoundly jeopardize the development of pharmaceutical care [17]. When performing pharmaceutical care, respondents spent a lot of time trying to identify DRPs for the patients but they hardly evaluated or even challenged doctors' prescriptions. There was literally no documentation of pharmaceutical practice and health education was only confined to the pharmacy setting which could explain why the pharmaceutical care processes often ended after the pharmacists' first encounter with their patients as shown in another study [20].

More than $40 \%$ of the respondents did not think that they could provide more comprehensive pharmaceutical care, indicating that there were challenges they were unable to resolve on their own. Similar to the result of previous studies, insufficient communication with physicians, lack of physical space, lack of time and lack of patient acceptance were reported to be the most important barriers by the respondents $[4,9,21]$. Lack of compensation mechanism for the service, lack of supportive policies and lack of time and opportunity to communicate with patients were also considered significant. Only $58 \%$ of the respondents thought all patients taking medicines would require pharmacists' help, reflecting a low level of reliance by patients on pharmacists 'professional service.

Taking into account other countries' experiences, the delayed development of pharmaceutical care could be explained by a lack of supportive policies and/or standards of practice to clearly define and mandate the professional obligations in the provision of pharmaceutical care as part of their essential practice. Without the necessary legal framework, neither the pharmacists nor other health care professionals could fully comprehend the importance of the pharmacist profession and the pharmaceutical care. This in turn posed a negative impact on doctors' acceptance of the service and willingness to communicate with pharmacists about patient's medication and health records. Patients for the same reason would not be keen in disclosing their medicine use with pharmacists and expecting any intervention. At the same time, pharmacy owners would not be motivated to adjust the physical environment in the pharmacy to appropriately accommodate the provision of the service. At the moment, pharmacists rarely had a chance to provide the service comprehensively. Without sufficient opportunities to practice, collection of data demonstrating the benefits of the service would be difficult. Until the cost and benefit of pharmaceutical care service can be justified with solid evidence, there is no condition for negotiation of a compensation mechanism for such service. Without reasonable financial incentives, pharmacy owners would not be motivated to incorporate the service into their business and to make manpower arrangement to free pharmacists out, from day-to-day front of shop duties to become dedicated to professional services.

Although lack of effective communication skills and lack of appropriate knowledge were not highly regarded as the major barriers by the 
respondents, they were rated the major barriers in other studies [22-25]. In this study, either the pharmacists had enough communication skills and clinical knowledge or they did not have enough practice opportunity to realize their shortcomings and the impact thereof on the provision of pharmaceutical care. Nevertheless, this area should be examined further for reassurance.

\section{Limitations of the study}

The study has several limitations. The current study was developed based on a thorough literature review. The questionnaire design was based on the theoretical basis of studies alike carried out abroad which may not fully address the situations specific to Macao and undermine the associated uncertainties of the results. Another limitation is the relatively small sample size of 100. Although it is proportionally significant given the Macao pharmacist workforce of 381 , the sample size may not be sufficient to minimize bias and may prevent precise generalization of the results. This study did not take into account the effect of the pharmacy business mode which has been reported as an influential factor in some studies. Subgroup analyses between the different types of pharmacies using a large sample size may be performed in the future to resolve this limitation.

\section{CONCLUSION}

Pharmacists in Macao have very positive attitude towards the provision of the service in the best interests of the patients and of the profession. However, there is a lack of responsibility to act proactively to provide the service and only some aspects of pharmaceutical care are currently conducted in their daily practice. Similar to findings in other studies, multiple perceived barriers are revealed, including insufficient communication with physicians, lack of working space, lack of time and lack of patient acceptance as the major ones. In the context of pharmacy practice situation in Macao, implementation of supportive policies and collection of evidence to demonstrate the benefits of pharmaceutical care are considered the foremost steps to alleviate the barriers for the service to leap forward from the infancy stage.

\section{ACKNOWLEDGEMENT}

The authors thank University of Macau for the support (grant no.MYRG2015-00072-ICMS-QRCM) given for this study.

\section{REFERENCES}

1. Simone M, Sabine V, Sabine W, Nico K. Understanding the pharmaceutical care concept and applying it in practice. Vienna: Austrian Federal Ministry of Health; 2010.

2. van Mil JW, Schulz M. A review of pharmaceutical care in community pharmacy in Europe. Harvard Health Policy Rev 2006; 7(1): 155-168.

3. Hepler CD, Strand LM. Opportunities and responsibilities in pharmaceutical care. Am J Hosp Pharm 1990; 47(3): 533-543.

4. Dunlop JA, Shaw JP. Community pharmacists' perspectives on pharmaceutical care implementation in New Zealand. Pharm World Sci 2002; 24: 224-230.

5. Jones EJ, Mackinnon NJ, Tsuyuki RT. Pharmaceutical care in community pharmacies: practice and research in Canada. Ann Pharmacother 2005; 39: 1527-1533.

6. Rossing C, Hansen EH, Traulsen JM, Krass I. Actual and perceived provision of pharmaceutical care in Danish community pharmacies: the pharmacists' opinions. Pharm World Sci 2005; 27: 175-181.

7. Bell JS, Vaananen M, Ovaskainen $H$. Providing patient care in community pharmacies: practice and research in Finland. Ann Pharmacother 2007; 41: 1039-1046.

8. BlumI BM, McKenney JM, Cziraky MJ, Elswick Jr R. Interim report from project ImPACT: hyperlipidemia. J Am Pharm Assoc (Wash) 1998; 38(5): 529-529.

9. Fang $Y$, Yang S, Zhou S, Jiang M, Liu J. Community pharmacy practice in China: past, present and future. Int $J$ Clin Pharm 2013; 35(4): 520-528.

10. Garião JA, Cabrita J. Evaluation of a pharmaceutical care program for hypertensive patients in rural Portugal. $J$ Am Pharm Assoc (Wash) 2002; 42: 858-864.

11. Gurwitz JH, Rochon $P$. Improving the quality of medication use in elderly patients: a not-so-simple prescription. Arch Intern Med 2002; 162: 1670-1672.

12. Hersberger KE, Botomino A, Mancini M, Bruppacher $R$. Sequential screening for diabetes-evaluation of a campaign in Swiss community pharmacies. Pharm World Sci 2006; 28(3): 171-179.

13. Maguire T, McElnay J, Drummond A. A randomized controlled trial of a smoking cessation intervention based in community pharmacies. Addiction 2001; 96(2): 325-331.

14. Snella $K A$, Canales $A E$, Irons $B K$, Sleeper-Irons $R B$, Villarreal MC, Levi-Derrick VE, Nelson AA. Pharmacyand community-based screenings for diabetes and cardiovascular conditions in high-risk individuals. J Am Pharm Assoc (Wash DC) 2006; 46(3): 370-377.

15. Berenguer B, La Casa C, De la Matta M, Martin-Calero M. Pharmaceutical care: past, present and future. Curr Pharm Design 2004; 10(31): 3931-3946.

16. Christensen DB, Farris KB. Pharmaceutical care in community pharmacies: practice and research in the US. Ann Pharmacother 2006; 40(7): 1400-1406.

17. Azhar S, Hassali MA, Taha A, Khan SA, Murtaza G, Hussain I. Evaluation of the perception of community

Trop J Pharm Res, April 2016; 15(4): 853 
pharmacists regarding their role in Pakistan's healthcare system: a qualitative approach. Trop J Pharm Res 2013; 12(4): 635-639.

18. Gholami K, Najmeddin F. Barriers to pharmaceutical care in Iran. J Pharm Care 2013; 1(2): 39-40.

19. Fang $Y$, Yang S, Feng B, Ni Y, Zhang K. Pharmacists perception of pharmaceutical care in community pharmacy: a questionnaire survey in Northwest China. Health Soc Care Community 2011; 19(2): 189-197.

20. Ngorsuraches S, Li SC. Thai pharmacists' understanding, attitudes, and perceived barriers related to providing pharmaceutical care. Am J Health Syst Pharm 2006; 63: 2144-2150.

21. Yordanova S, Pertkova V. Pharmaceutical care in some European countries, Australia, Canada and USA. Int J Pharm Pharm Sci 2013; 2(5): 2291-2308.
22. Ibrahim A, Scott J. Community pharmacists in Khartoum State, Sudan: their current roles and perspectives on pharmaceutical care implementation. Int $J$ Clin Pharm 2013; 35(2): 236-243.

23. Liekens S, Smits $T$, Laekeman G, Foulon $V$. Pharmaceutical care for people with depression: Belgian pharmacists' attitudes and perceived barriers. Int J Clin Pharm 2012; 34(3): 452-459.

24. Song $M$, Ung COL, $\mathrm{Hu} H$, Wang $Y$. Community pharmacists' perceptions about pharmaceutical care of OTC western medicine: a survey in Harbin of China. Int J Clin Pharm. 2015; 37(6): 1014-1020.

25. Lo UM, Hu H, Ung COL. Physicians' and pharmacists' experience and expectations of the roles of pharmacists: insights into hospital setting in Macau. Trop $J$ Pharm Res. 2014; 12(6): 1077-1085. 